\title{
Reminiscências da Violência Estatal: A Reparação Psíquica Através de uma Clínica Política
}

\author{
Natália Centeno Rodrigues \\ Universidade Federal do Rio Grande, RS, Brasil. \\ Francisco Quintanilha Véras Neto \\ Universidade Federal do Paraná, PR, Brasil. \\ Rodrigo Fernandes Teixeira \\ Universidade Federal do Rio Grande, RS, Brasil.
}

Resumo: $\mathrm{O}$ artigo se propõe a abordar o caminho escolhido pelo Estado brasileiro ao realizar a transição política da ditadura civil-militar (1964-1985) para uma democracia constitucional, focando nas práticas reparatórias adotadas até constituir o projeto responsável por fornecer a reparação psíquica, o Clínicas do Testemunho. O caminho metodológico escolhido foi o dialético, pois nos permite a compreensão do processo histórico em questão. Para realizarmos a pesquisa, adotamos os seguimentos procedimentos técnicos: a pesquisa de cunho bibliográfico e documental. Nossa abordagem se compõe de quatro momentos: inicialmente traçamos reflexões sobre a repressão ditatorial construindo o cenário. Depois passamos a abordar como o governo militar começou o processo transicional e quais foram os caminhos percorridos, as possibilidades e os espaços desenvolvidos para que os afetados e a sociedade tivessem direitos humanos respeitados e efetivados. Enfim, passamos a abordar o Clínicas do Testemunho, sede Porto Alegre, como projeto reparatório que visa satisfazer demandas, essas de cunho individual - centradas nas figuras dos afetados, e coletiva, que diz respeito a toda sociedade, que recalcou esse passado autoritário. Aqui abordamos o trauma socioindividual como algo que impacta essa clínica política realizada após um longo lapso temporal, nos propomos pensar como isso afeta e qual a importância desse projeto centrado nos indivíduos, em suas vivências e seus testemunhos. Assim, concluímos que o Clínicas atua como um dispositivo de reparação que problematiza as heranças autoritárias e possibilita para os afetados um paradigma de cuidado, no qual o acolhimento e a escuta, são peças chaves para respeitarmos a alteridade.

Palavras-chave: Ditadura Civil-Militar, Testemunho, Memória, Reparação Psíquica, Clínica Política. 


\title{
Reminiscences of State Violence: The Psychological Repair Through a Political Clinic
}

\begin{abstract}
The article proposes to approach the path chosen by the Brazilian state when making the transition from the civil - military dictatorship (1964-1985) to a constitutional democracy, focusing on the reparative practices adopted until it constituted the project responsible for providing psychic reparation, the Clínicas do Testemunho. The methodological path chosen was the dialectic, since it allows us to understand the historical process in question. To carry out the research we adopt the following technical procedures: bibliographical and documentary research. Our approach is composed of four moments. Initially we drew reflections on the dictatorial repression constructing the scenario. Then we began to address how the military government began the transitional process and what paths, possibilities and spaces were taken, so those affected and the society have their effective human rights respected. Finally, we went to address the Clínicas do Testemunho, Porto Alegre headquarters, as a reparatory project that seeks to meet individual - centered on the figures of the affected-, and collective - related to the society as a whole, which emphasized this authoritarian past- demands. Here we approach socio-individual trauma as something that impacts this political clinic performed after a long time, and we propose to think how this affects and how important this project that focuses on individuals, their experiences and their testimonies is. Thus, we conclude that Clínicas acts as a device of reparation that problematizes authoritarian inheritances and offers a paradigm of care for those affected, in which the reception and listening are key pieces to respect otherness.
\end{abstract}

Keywords: Civil-Military Dictatorship, Witness, Memory, Psychic Reparation, Political Clinic.

\section{Reminiscencias de la Violencia Estatal: La Reparación Psíquica a Través de una Clínica Política}

Resumen: El artículo se propone abordar el camino escogido por el estado brasileño al realizar la transición política - de la dictadura civil-militar (1964-1985) hacia una democracia constitucional, enfocándose en las prácticas de reparación adoptadas hasta constituir el proyecto responsable de proporcionar la reparación psíquica, el Clínicas do Testemunho. El camino metodológico escogido fue el dialéctico, pues nos permite la comprensión del proceso histórico en cuestión. Para realizar la investigación adoptamos los siguientes procedimientos técnicos: la investigación de cuño bibliográfico y documental. Nuestro enfoque se compone de cuatro momentos. Inicialmente trazamos reflexiones sobre la represión dictatorial construyendo el escenario. Después pasamos a abordar cómo el gobierno militar comenzó el proceso transicional y cuáles fueron los caminos recorridos, las posibilidades y los espacios desarrollados para que los afectados y la sociedad tuvieran derechos humanos respetados y efectivos. Finalmente, pasamos a abordar las Clínicas do Testemunho, sede Porto Alegre, como proyecto de reparación que busca satisfacer demandas, esas de cuño individual - centrado en las figuras de los afectados, y colectivo, que concierne a toda la sociedad, que recalcó ese pasado autoritario. Aquí abordamos el trauma socio-individual como algo que impacta esa clínica política realizada después de un largo lapso temporal, y nos proponemos pensar cómo afecta y cuál es la importancia de ese proyecto centrado en los individuos, en sus vivencias y sus testimonios. Así, concluimos que el Clínicas actúa como un dispositivo de reparación que problematiza las herencias autoritarias y posibilita para los afectados un paradigma de cuidado, en la que la acogida y la escucha son piezas claves para respectar la alteridad.

Palabras clave: Dictadura Civil-Militar, Testimonio, Memoria, Reparación Psíquica, Clínica Política. 


\section{O passado ditatorial, algumas reflexões introdutórias}

A violência aparece como matriz do pensamento autoritário brasileiro, e nos constitui antes mesmo de existirmos como país. Somos sujeitos históricos marcados por processos de assujeitamento e subordinação, um tecido social composto pelo genocídio dos povos originários, pela herança escravocrata, pelos arbítrios da ditadura varguista e por um passado autoritário civil-militar, passado esse ainda recalcado pelo corpo social. Entendemos que é necessário problematizar não só o passado ditatorial, mas principalmente as sequelas, os entulhos e as reminiscências autoritárias que ainda seguem afetando nossa sociedade.

Durante a ditadura civil-militar brasileira (19641985), a atuação estatal foi utilizada como um mecanismo articulado com o intuito de dizimar os opositores, os "inimigos internos", o aparato repressivo foi estruturado de acordo com os princípios da Doutrina de Segurança Nacional (DSN). Em síntese, Enrique Padrós (2005) nos diz que o terrorismo de estado consiste na violência estatal, que viola o direito e extrapola a legalidade constitucional. Além das vias repressivas diretas, marcadas pela violação física, outros mecanismos foram utilizados, como o aparelho propagandístico, o aparato jurídico-legal, o aporte administrativo-estatal e a estrutura psicológica, todos esses foram utilizados para dar suporte a atividades clandestinas ou não, que visavam conseguir o controle daqueles que o questionaram. Para isso, utilizando-se do "medo como uma das estratégias de dominação política" (Bauer, 2006, p. 122), o terrorismo estatal se estendeu e atingiu toda a sociedade brasileira (Padrós, 2005, p. 122-123).

Ao tratarmos da ditadura civil-militar brasileira, é fundamental destacarmos o apoio dos setores civis e de entidades empresariais, estes setores tornaram o terrorismo de Estado, um amplo modo repressivo, similar a um sistema estatal, que não se resumiu a conter corpos, repreender fisicamente seus inimigos, o que já é algo horrível e devastador. As torturas, as perseguições deixam amplas marcas nos corpos dos que foram violados, e foram além, marcaram integralmente o tecido social. $\mathrm{O}$ medo da clandestinidade e da violência estatal funcionou como um amortecedor da resistência e auxiliou a neutralizar algumas respostas da sociedade civil. Tais posturas colaboraram para que o efeito psicológico da violência do Estado se tornasse onipresente e anônimo, preservando o governo das denúncias sobre as violações de direitos humanos que lhe eram atribuídas, que somente na segunda metade da década de 1970 tornaram-se públicas.

A tortura foi um método de aniquilação individual que gerou uma pedagogia baseada no medo. $\mathrm{O}$ ato de torturar nada mais é do que um exercício de poder. Poder que reflete em toda sociedade em forma de medo, silêncio e indiferença em relação ao outro torturado. Dessa forma, vemos que a tortura é uma prática social que "é encenada a três: o poder que tortura, o torturado e a sociedade" (Keil, 2004, p. 59). No imaginário social é fácil relacionar os dois primeiros elementos com o ato da tortura, pois estão imbricados diretamente, já que vivenciam em loco o ato.

Entretanto, a sociedade assumiu um papel - de telespectadora dessas atrocidades, não demonstrando algum tipo de afetação com os sujeitos aniquilados e, muitas vezes, legitimando o governo ilegítimo e dizendo que tal fato ocorrera pois havia um motivo. Cabe uma ressalva ao falarmos do papel da sociedade como conivente: não estamos nos esquecendo dos movimentos que lutaram pelas liberdades e direitos humanos durante a ditadura civil-militar, nos referimos à parcela da população que não se envolveu politicamente.

Em vista do exposto, o corpo torturado sofre marcas atrozes, inscritas pela violência, pelo medo e pelos traumas da tortura. Conforme Kehl (2004, p. 11), essa vivência tem a capacidade de separar o corpo e o sujeito (sujeito de vontade e ação), já que a relação entre torturador e torturado é permeada pela linguagem, indissociável do corpo, e que mantém a relação do sujeito com o mundo das representações, logo, o sujeito é aniquilado integralmente perante ao laço social, ou seja, a violência ditatorial deixa uma escritura no sujeito. Assim nos surge a seguinte questão: há necessidade de o governo brasileiro promover um projeto de reparação psíquica destinado aos sujeitos que foram afetados pela violência estatal ditatorial, mesmo passado mais de 20 anos do seu fim?

Esse escrito possui como objetivos compreender de que modo um projeto governamental de reparação psíquica pode e serve para atender demandas das pessoas afetadas (direta e indiretamente) e do laço social; analisar o modo como a sede de Porto Alegre do Projeto Clínicas do Testemunho realizou suas atividades e de que forma essas sinalizam ou não a importância da existência de um projeto de reparação psíquica; 
rascunhar um traço sobre a herança autoritária que permanece em nossa sociedade e representa muitos silêncios que não foram (re)significados.

\section{0 percurso metodológico}

Para esse artigo, adotamos o método dialético, pois esse nos permite a compreensão do processo histórico das mudanças e dos conflitos sociais (Gil, 1987, p. 31). Essa abordagem metodológica se mostra como forma pertinente de investigar a realidade e, desse modo, nos possibilita compreender como, passadas quase três décadas do fim da ditadura civil-militar, o Estado brasileiro estabelece parceiras com sociedades civis, com o intuito de fornecer a reparação psíquica, através da implementação dos dispositivos de apoio e atenção aos indivíduos, os quais foram afetados pelos efeitos da violência estatal.

Nossa escolha teórica justifica-se, na medida em que o referido método nos permite abordar o fenômeno estudado por diversos aspectos, buscando compreender e estudar as suas relações e conexões, mantendo a complexidade do objeto pesquisado (Gil, 1987, p. 32), ou seja, nos permite compreender como as permanências autoritárias ainda afetam a nossa sociedade e como a atuação do Projeto Clínicas do Testemunho. Para desenvolver a pesquisa adotamos os seguintes procedimentos técnicos: de nível exploratório realizamos pesquisa de cunho bibliográfico e documental.

A seleção bibliográfica para pensar o processo transicional brasileiro foi multidisciplinar, elencamos referências da área da história, do direito, da ciência política e da psicanálise com o intuito de dialogarmos e respeitarmos a complexidade do processo social abordado. Já a escolha bibliográfica em relação ao Projeto Clínicas do Testemunho, partiu de uma base teórica encontrada nos materiais produzidos pelos núcleos do projeto, consistem esses essencialmente em livros. O aporte psicanalítico foi a opção teórica por nós elencada devido ao fato de compreendermos que o mesmo dá conta das questões relativas a reparação psíquica, o testemunho, o falar, o ato de escutar, a sociedade, o sujeito e o trauma. Além disso, as sedes do Projeto seguem orientação psicanalítica, fator que balizou nossa escolha teórica. A base documental analisada consiste no relatório produzido pela sede de Porto Alegre do Projeto Clínicas do Testemunho, no qual a Sigmund Freud Associação
Psicanalítica no qual apresentou os resultados do projeto-piloto (2013-2015).

Assim, o caminho percorrido nesse escrito parte de uma breve compreensão do contexto repressivo. Para assim caracterizarmos como a transição política foi negociada, como passamos de uma ditadura civil-militar para uma democracia constitucional. Após isso, nos dedicamos a demonstrar como o processo de reparação política ocorreu em nosso país até a criação do projeto Clínicas do Testemunho que estabeleceu uma ruptura dentro de tais práticas, pois possibilita romper com a figura do sujeito silenciado ao abordar as vivências individuais frente ao terrorismo estatal. Ao fim, nos debruçamos a pensar o trauma e como esse impacta nessa clínica política desenvolvida pelo projeto, para assim refletimos como o Projeto Clínicas do Testemunho se apresenta como uma potência significativa.

\section{A transição à brasileira, o papel da lei de anistia}

Em nosso escrito, para abordamos a transição política, partimos da lei de anistia, remontamos a sua promulgação no ano 1979, pois a referida lei até hoje segue configurando o cenário transicional brasileiro. Entendemos que a transição política "trata-se, pois, de um processo de negociação que conduz à substituição no poder e à instauração de certas regras pelas quais, tal poder será exercido no futuro" (Carrillo, 2009, p. 32). Desta forma, mesmo sobre o regime democrático, observamos as permanências do legado autoritário, que são configurações institucionais que "sobrevivem à transição democrática e intervêm na qualidade e na prática das democráticas pós-autoritárias" (Pereira, 2010, p. 239). A aparência de legalidade e a institucionalidade serviram para que a ditadura se perdurasse por muitos anos e suas raízes se fazem presentes no contexto atual.

Em agosto, dois projetos legislativos foram discutidos no Congresso Nacional sobre a anistia. O projeto defendido pela oposição tinha como bandeira "anistia ampla, geral e irrestrita" a todos que opuseram o governo e exerceram o direito de resistência. Já o projeto governista propunha uma anistia parcial e restrita, pois não visava conceder liberdade a todos os presos políticos. Ao longo do mês, os projetos foram discutidos e, no dia 28 de agosto de 1979, o General ditador Figueiredo sancionou a lei de 
anistia, que correspondia aos interesses governistas, relata Mezzaroba (2006, p. 50).

A anistia simbolizou um avanço político, já que mais de cinco mil brasileiros foram beneficiados com a sua aprovação. Também constituiu uma barreira, devido à interpretação judicial cunhada na época atribuiu à lacuna legal o sentido de que aqueles que agiram abarcados pelo manto estatal estavam anistiados por terem cometidos tais violações aos direitos humanos de modo conexo aos crimes políticos. Essa interpretação até hoje veda a instauração de processos judiciais que buscam responsabilizar os perpetradores de direitos humanos. Dessa forma, a anistia ainda hoje representa um impeditivo transicional, ao vedar a responsabilização judicial dos agentes violadores de direitos humanos. Como exposto acima, entendemos que a anistia no Brasil representou uma "conciliação quase (im)posta” (Cunha, 2010, p. 35), tendo em vista que os governantes lograram êxito ao aprovar o seu projeto e conseguiram escapar da responsabilização pelos atos cometidos durante o período ditatorial. Dessa forma, percebemos que a nossa transição política foi caracterizada por (re)configuração, transformação e não ruptura, assenta Abrão (2012).

\section{O que fica da ditadura na transição? As práticas pelo governo brasileiro até implementar o projeto de reparação política}

A anistia exerceu centralidade na transição e outros mecanismos transicionais foram instaurados com o intuito de efetivarem direitos transicionais, como o direito à verdade, à memória, à justiça e as instituições democráticas. A primeira medida reparatória proposta pelo governo brasileiro foi o reconhecimento oficial do óbito daqueles que desapareceram em decorrência da participação ou acusação de participação em atividades políticas, concedido através da Lei no 9.140 de 1995 (Brasil, 1995).

Já em 2002, com a promulgação da Lei no 10.559 (Brasil, 2002), foi instaurada a Comissão de Anistia, órgão vinculado ao Ministério da Justiça, ao qual foi atribuída a função de julgar os pedidos de anistia política e de estabelecer se haverá ou não a concessão de reparação de cunho pecuniária. Tal dispositivo legal, regulamentou o artigo $8^{\circ}$ do Ato das Disposições Constitucionais Transitórias, assim, estabeleceu qual o procedimento necessário para que alguém seja declarado anistiado político e instituiu os limi- tes constitucionais de quem pode requerê-la: pode requerer toda e qualquer pessoa que foi afetada pela perseguição estatal, por motivação exclusivamente política. Assim, demarcou que somente as pessoas que foram perseguidas/afetadas pela atuação estatal repressiva do governo ditatorial poderiam requerer.

A Comissão de Anistia tornou-se órgão-chave na transição e, em 2008, estabeleceu um procedimento móvel de julgamento dos pedidos de anistia, criando as Caravanas de Anistia com o objetivo tornar público os julgamentos e assim difundir as histórias sobre o nosso passado. Além disso, criou um espaço de fala pública destinado aos sujeitos que foram perseguidos, constituindo o primeiro espaço no qual o papel ativo ao afetado, concedendo voz, e ao fim de tudo, o representante estatal assume o espaço e pede desculpa em nome do estado brasileiro pelas violações que foram cometidas.

Ainda no cenário transicional a lei de anistia foi questionada judicialmente, o Conselho Federal da Ordem dos Advogados do Brasil ajuizou junto ao Supremo Tribunal Federal (STF) uma Ação de Descumprimento de Preceito Fundamental (ADPF). A ADPF $n^{\circ} 153$ buscava que o judiciário realizasse uma nova interpretação legal, pedia que fossem julgados individualmente os pedidos de anistia, a fim de verificarmos se era cabível ou não a concessão da anistia aos agentes violadores, e buscava revestir de materialidade a questão da conexão dos crimes prevista na lei. Os ministros do STF julgaram em abril de 2010 a ação proposta como improcedente, pois entenderam que uma revisão agora era inconcebível e compreenderam a anistia como um pacto de pacificação social.

Em novembro de 2010 foi proferida uma sentença condenatória pela Corte Interamericana de Direitos Humanos (Corte IDH) que julgou o Brasil responsável pela violação de direitos humanos ocorridas durante a Guerrilha do Araguaia, no "Caso Gomes Lund e Outros versus Brasil”. A sentença se compôs de inúmeros dispositivos, dois deles foram tornaram-se lei pelo governo brasileiro, a Lei $\mathrm{n}^{\circ}$ 12.527 (Brasil, 2011a) e a Lei ${ }^{\circ} 12.528$ (Brasil, 2011b), ambas de 2011. A primeira regulamentava o acesso público aos documentos, modificou o acesso, a sistematização e a publicação dos documentos e informações públicas. Já a segunda lei criou a Comissão Nacional da Verdade (CNV) no âmbito da Casa Civil da Presidência da República, que atuou de maio de 2012 até dezembro de 2014, quando publicou o seu 
relatório final, composto por três volumes, no qual foram explicitadas as investigações e as apurações feitas sobre o contexto repressivo, as violações de direitos humanos e a investigação dos mortos e desaparecidos políticos. Essas informações foram sistematizadas com a intenção de que fossem conhecidas pela população, evidenciando que o governo ditatorial cometeu crimes lesa humanidade, tais como o desaparecimento forçado, ocultação de cadáveres, torturas e execuções.

A sentença condenatória da Corte IDH, em seu $11^{\circ}$ ponto resolutivo, atribui ao Brasil a obrigação de criar mecanismos de atenção médico e psicológica voltados a atender aqueles que foram afetados (direta e indiretamente) pela ditadura civil-militar. Atendendo esse aspecto o país, criou o Projeto Clínicas do Testemunho vinculado à Comissão de Anistia. $\mathrm{O}$ edital que visava à criação do projeto-piloto foi publicado em 2012, e sua atuação iniciou no ano seguinte. O referido projeto buscava criar espaços destinados a atenção e apoio psicológico, aos afetados pela violência estatal. Dessa forma, em resposta ao primeiro edital tivemos a criação de quatro sedes, duas situadas em São Paulo, uma no Rio de Janeiro e outra em Porto Alegre. Integrou-se a rede uma clínica que foi criada em Recife, subsidiada pelo governo estadual, e se vinculou ao projeto, para atuar na mesma perspectiva.

Fazendo uma análise sintética compreendermos que a nossa justiça de transição assenta-se em mecanismos jurídicos que concedem direitos aos afetados políticos - como a reparação política, econômica e moral. Esse processo parte da lei de anistia, que se constitui como um impeditivo transicional, pois impossibilita a responsabilização penal dos agentes violadores dos direitos humanos. Evidenciando-a como um entulho autoritário, que representa a nossa cultura jurídica "conciliadora" (Baggio, \& Miranda, 2010, p. 162) e naturalizadora das violações que a sociedade brasileira foi (e ainda é) submetida.

Nos últimos anos, observamos que finalmente o protagonismo começou a ser concedido aos afetados pela ditadura civil-militar. Modificação representativa, pois são os afetados que podem contar o que lhes ocorreu e transmitir suas vivências, tornando-as experiências comunicáveis, evidenciando as marcas que esse passado autoritário deixou em suas vidas. Surgiram espaços como o dispositivo final da Caravana de Anistia, e o espaço instalado para a oitiva dos depoimentos junto a Comissão Nacional da Verdade, tais espaços que modificaram o protagonismo e exercem um papel simbólico, apesar de não estarem em conformidade com o paradigma da recepção, a escuta e o acolhimento. O Projeto Clínicas do Testemunho surge e assume como objetivo para si a criação de espaços públicos alicerçados no acolhimento e na escuta daqueles que se entendem afetados pelas violências estatais e utiliza o testemunho, como seu dispositivo central, para que os mesmos possam repassar e escovar a história de suas vidas a contrapelo (Benjamin, 2012, p. 245).

Tomamos os testemunhos dessas vivências por parte de quem as sofreu direta ou indiretamente, como base desse trabalho clínico-político. Elegemos os testemunhos e não depoimentos, pois, ao pensarmos na ideia de um depoimento, fechamos as possibilidades de fala e instauramos uma busca por fatos e verdades que necessitam ser comprovadas ou refutadas em seu caráter jurídico. Ao escolhermos os testemunhos se abre uma possibilidade de construção de subjetividade e de descontinuar uma história hermética e criar um lugar para o sujeito, já que para testemunhar, não há apenas a necessidade de fala, mas também tem que haver uma escuta (papel aqui considerado como do terapeuta) para conferir voz aos sentimentos mudos, para assim conseguir compor novas tramas de sentido para as memórias traumáticas (Indursky, \& Szuchman, 2014, p. 58).

O testemunho se instaura em outro lugar. A linguagem do testemunho cria uma realidade, que vai além da palavra proferida e torna-se um acontecimento, enuncia "uma verdade que só a vítima pode produzir porque pertence à sua experiência da violência" (Ruiz, 2014, p. 64). Assim, o testemunho, "se tornou a forma privilegiada de narrar uma experiência qualificada de in-transmissível justamente por aqueles que tentaram transmiti-la" (Koltai, 2016, p. 24), buscando uma forma de transformar o excesso do real em jogo traumático, tendo sempre em mente uma posição ética, na transmissão daquilo que é indizível. "Os testemunhos realizam a passagem de uma memória que era individual para o coletivo, $\mathrm{o}$ ato de testemunhar evita o esquecimento histórico e se constitui como elemento de suma importância para aqueles que vivenciaram as experiências traumáticas" (Rodrigues, \& Véras Neto, 2016, p. 151). Não só os indivíduos necessitam desse testemunho, mas sim o tecido social carece de tais narrativas porque 
suas vivências são permeadas pela matriz autoritária, sua institucionalidade é marcada por tais processos. As narrativas testemunhais possibilitam a construção de uma memória pública, assentada em valores democráticos e antiautoritários, na medida em que elas abrem fissuras na política de silenciamento, que ainda vige no Brasil.

Assim compreendemos que o Projeto Clínicas do Testemunho surge como um quarto eixo de reparação, complementando as reparações econômicas (concessão de reparação financeira), coletiva (marcada pelas iniciativas de memória) e a moral (que é composta pelo pedido de desculpa em nome do Estado brasileiro). A atuação do projeto visa conceder a atenção terapêutica, sua prática consiste em múltiplas frentes, e objetiva capacitar profissionais para lidar com as violências institucionais, a fim de reparar os danos, aqui compreendidos como transicionais, pois se mantêm presentes em nosso tecido social. Os danos sociais são transgeracionais, que perpassam as gerações, a cultura institucional e também permanecem e se (re)configuram de modo autoritário.

O projeto atribui uma potência ao testemunho, como disparador coletivo e por entender que sem uma construção de uma narrativa pública sobre a violência autoritária ditatorial, não conseguiremos alicerçar uma sociedade democrática. E essas narrativas devem ser construídas a partir do paradigma do cuidado, da escuta e da não (re)traumatização.

\section{Como pensar o trauma na realização do projeto Clínicas do Testemunho}

Para trabalharmos a noção de trauma, pensaremos a partir da noção que a psicanálise fornece sobre o tema. Breuer e Freud (1995, p. 42) percebem o evento traumático em uma impossibilidade de lembrar, entretanto, com a capacidade de inscrever sintomas físicos que estão em desacordo com a realidade anterior ao trauma. Os autores pensaram que a maneira de tratar a histeria estaria de acordo com um processo, nos qual as pacientes conseguiriam lembrar do evento causador liberar o afeto que acompanha a experiência traumática.

Percebemos, então, que essa noção permeia a obra de Freud desde o início como algo que constitui a realidade, que tem poder de modificar e afetar de diversas maneiras o aparelho psíquico "O 'recalcamento' da lembrança de uma experiência sexual aflitiva, que ocorre em idade mais madura, só é possí- vel para aqueles em quem essa experiência consegue ativar o traço mnêmico de um trauma da infância" (Freud, 1997, p. 98). O trauma então é fundamental para o estudo psicanalítico acerca do sujeito e suas vivências no mundo.

Após alguns anos essa teoria teve desdobramentos na obra freudiana, porém, estes não são pertinentes ao nosso trabalho. Ferenczi (2011a), um dos psicanalistas da geração de Freud, agrega a experiência de ter vivenciado os horrores da primeira grande guerra (1914-1918) em seus escritos sobre o trauma, o que permitiu lançar um outro olhar as questões relativas ao traumatismo psíquico. $\mathrm{O}$ autor propõe que a consequência imediata do trauma é a angústia, que consiste em um sentimento de incapacidade de adaptação a essa situação.

O desprazer cresce e exige uma válvula de escape. Tal possibilidade é oferecida é oferecida autodestruição, a qual, enquanto fator que liberta da angústia, será preferida ao sofrimento mudo. O mais fácil de destruir em nós é a consciência, a coesão das formações psíquicas numa entidade: é assim que nasce a desorientação psíquica (Ferenczi, 2011b, p. 127).

A partir do tratamento de 200 combatentes, Ferenczi percebeu um quadro sintomatológico inespecífico e tardio e que havia sequelas da guerra que não eram apenas provocadas por lesões físicas no tecido cerebral, no entanto, eram formadas por traumatismos oriundos dessas vivências. Nesse estudo, o autor percebe que um dos sintomas mais comuns eram os pesadelos que remontavam as situações trágicas vividas no fronte de batalha, ideia que modifica um pouco o parâmetro Freudiano dado anteriormente, pois a pessoa, mesmo que por vias inconscientes, se lembra do acontecimento (Ferenczi, 2011a, p. 299).

Ainda sobre a Primeira Guerra Mundial, é conveniente lembrar a constatação de Walter Benjamin que percebe que os "combatentes voltavam silenciosos do campo de batalha, mais pobres em experiências comunicáveis, e não mais ricos" (Benjamin, 2012, p. 124). Tal afirmação ganha mais sentido se relacionarmos com a ideia trazida por Ferenczi sobre o mesmo período:

Esses pacientes ainda não se refizeram de seu pavor, mesmo que já não pensem consciente- 
mente no transe por que passaram e até se mostrem, por vezes, alegres e de bom humor, como se seu espírito não estivesse torturado, de forma alguma, por tão horríveis lembranças (Ferenczi, 2011a, p. 297).

O que impera, ao fim, é o silenciamento, que relega aos sujeitos traumatizados uma espécie de história impossível de ser contada. Após o holocausto, o problema apenas tomou proporções mais complexas, um exemplo clássico, porém ainda pertinente, diz respeito ao sonho de Primo Levi, no qual ele volta do campo de concentração onde esteve preso e, ao começar a narrar as suas experiências em face ao horror, as pessoas ao seu redor passam a deixar o recinto, demonstrando o desinteresse em ouvir aquela narrativa (Levi, 1988, p. 60).

Todos esses fatores históricos colaboram para entendermos o fenômeno da tortura e das ditaduras civis-militares na América Latina sob a ótica do trauma e sobre os efeitos sociais das mesmas. A tortura, ou demolição do sujeito, ocorre em três etapas para Viñar (1993) que diz que há uma fase de aniquilação do indivíduo, seguido por uma desordem profunda de convicções, a terceira etapa é de reenlace, a reorganização do sujeito com aquela situação indizível. Há, por fim, os caracteres individuais que se colocarão acerca do sujeito que sofreu com a violência. A sintomatologia será um reflexo de um impacto em nível pessoal, aspectos múltiplos partilhados e a situação de repressão mais especificada (Lira, Weinstein, 1984). Normalmente essa situação não tem uma elaboração fácil, ainda mais nos casos onde o estado que deveria proteger o sujeito acaba por destruí-lo.

Devemos observar esse sofrimento humano a partir de uma ideia de sociedade. Kehl (2010, p. 125126) propõe que socialmente temos um universo de experiências compartilhadas por todos por intermédio da linguagem. Porém, as pessoas afetadas pelos regimes de exceção, mais diretamente o caso brasileiro da ditadura civil-militar, tem uma gama de experiências violentas não compartilháveis pela fala, fazendo com que vivam em uma espécie de "universo paralelo". Consequentemente, ainda de acordo com a autora, essas experiências não fazem parte da memória coletiva, memória que institucionalmente serviu para aterrar o terror dos torturados, resultado de um estado que não reconhece que atuou (através de seus agentes) na aniquilação da vida.
A história desse período autoritário é muito controversa, pois o silenciamento fez com que a história oficial ocultasse as barbáries promovidas pelo estado durante 21 anos. Porém, sabe-se que todo o aparato institucional disponível foi utilizado para fins de controle e de punição social para os que resistiram, isso não furta o papel das instituições de saúde. É sabido que médicos e psicólogos acompanhavam alguns centros de tortura no Brasil, vide o que denuncia Vianna (1994) que conta os absurdos promovidos pelo psicanalista Amilcar Lobo, que trabalhou junto as forças do exército na tortura de civis.

Dessa forma, a atuação da Psicologia junto aos afetados pela ditadura brasileira tem um papel bastante complexo, pois, embora haja alguns caracteres de resistência, sua prática também foi utilizada como aliada do braço do estado. O trabalho de escuta a partir daí necessita de uma construção muito elaborada, pensar não somente as técnicas, mas as condições de escuta e intervenção possíveis para que se possa (re) contar a história brasileira a partir da fala silenciada.

Retomando Keil (2004, p. 59), ela lança luz sobre o fato de que toda e qualquer tortura ou violência cometida durante a ditadura foi vista por, no mínimo, três forças, o estado torturador, aqueles que foram vítimas e a sociedade que permitiu que tais episódios acontecessem. Essa consideração coloca esses eventos em outro eixo, no qual a sociedade participa ativamente de todo o processo, tanto de causa como de reparação da violência.

Além disso, pensamos, por meio de Maria Rita Kehl, que as sevícias do corpo deixam marcas no sujeito como todo, principalmente pela palavra que o torturador deseja ouvir, que nada tem a ver com a que o outro, subjugado por sua violência, tem a dizer. Como diz a autora: "Resta ao sujeito que se identifica com o corpo que sofre nas mãos do outro o silêncio, como última forma do domínio de si" (Kehl, 2004, p. 10). Como conceituação geral dentro desse escrito entendemos o trauma, assim:

A intensidade excessiva do trauma calcina o sentido e a palavra não consegue organizar o relato e nada amarra o elemento temporal, instalando-se uma descontinuidade que a psicanálise chamou de a posteriori. O que se pode dizer, o que se pode lembrar, apresenta-se como falho, tem uma intensidade que não pode ser dita, algo se inscreve e escapa (Perrone, \& Moraes, 2014, p. 32). 
A partir da instauração do Clínicas do Testemunho, observamos algumas mudanças no que tange a reparação psíquica em nosso país. Sobre o tempo que levou para essa reparação ser efetivada, observamos um enorme hiato, um espaço geracional que determinou a formação psíquica das futuras gerações (Trachtenberg, 2013 p. 83). No entanto, apesar do longo tempo, isso não configura uma impossibilidade do trabalho. Conforme pontua Altounian (2012, p. 109) sobre o genocídio armeniano, há um trabalho gestacional dessa potência de testemunhar, que implica em um trabalho feito não por quem fala, mas por quem escuta, um trabalho que pode levar gerações para poder existir. Uma atividade que inverte um pouco da demanda, ou seja, a demanda de falar também depende da demanda de escutar, bem como dito anteriormente nas impressões de Primo Levi.

\section{A potência do testemunho $\mathrm{e}$ a experiência do Clínicas do Testemunho em Porto Alegre}

O Clínicas do Testemunho se instaura como uma medida que faltava no país, dentro do cenário transicional brasileiro, necessitava de um espaço destinado a problematizar os efeitos psíquicos, deixados no tecido social e nos sujeitos que foram afetados. O Clínicas "parte do acolhimento das dores, dos afetos, dos signos, das palavras isoladas, e acompanha as intenções e os movimentos que podem promover a passagem daquilo que aparece cravado na carne como um signo, a um saber mais subjetivado" (Vannuchi, 2014, p. 03). Nesse espaço, o acolhimento é a ferramenta fundamental. O papel dos terapeutas "é de testemunha da história familiar” (Ocariz et al., 2014), como um espaço transferencial, se constitui como um espaço de reconhecimento da dor.

A equipe do Clínicas, sede Porto Alegre, é composta por profissionais capacitados, que estão preparados para lidar com os traumas oriundos da violência de Estado, esses se destinam a acolher e escutar tais narrativas, evitando a naturalização do "silenciamento - capaz de atravessar gerações - e assim perde-se o elo de responsabilidade entre os acontecimentos fundantes do devir histórico" (Losicer, 2015, p. 32). $\mathrm{O}$ projeto permite o deslocamento das histórias que antes eram apenas individuais para o coletivo, para o tecido social, através de alguns de seus dispositivos. E vai além, seu formato potencializa "o ato de testemunhar” (Vital Brasil, 2015, p. 43), pois, ao quebrar o silêncio, a clínica ganha uma outra dimensão, já que retira o passado da esfera privada individual, e lança para o coletivo a experiência traumática que foi submetido, sendo assim o testemunho se torna "um chamado à responsabilidade do Estado e uma convocação ao reposicionamento ético de quem se torna uma 'testemunha do testemunhado'” (Kolker, 2015, p. 62).

Ao pensar o projeto, nos cabe trazer alguns dos desafios que foram enfrentados pelo projeto Clínicas, sede Porto Alegre. Quando a equipe começou a execução do projeto, não havia um levantamento prévio de demanda, ou seja, criou-se o projeto sem saber se haveria pessoas interessadas no mesmo, assim foi necessário realizar a aproximação e divulgação do projeto para que os primeiros interessados se aproximassem. Outra questão enfrentada foi que no primeiro momento as pessoas compreendiam a proposta do Clínicas como mero dispositivo clínico individual, e não compreendiam como uma potência clínica política. Além disso, houve pessoas que resistiram e não realizaram a aproximação por se tratar de um projeto financiado pelo governo brasileiro, o mesmo agente violador de outros tempos. Se fez necessário pensar "a significância do Estado, ele mesmo ofertar um projeto de reparação psíquica, pois a possibilidade de ocorrer um tratamento, seja individual ou grupal, é investida desde então pelo reconhecimento do Estado de que ele é responsável pelo dano feito" (Sigmund Freud Associação Psicanalítica, 2015). Compreendemos que é necessário que a reparação parta do ente violador para que possamos falar em reparação psíquica. Todas essas questões foram desenvolvidas no intuito que a equipe conseguisse construir uma base para desenvolverem o trabalho, as questões por nós aqui levantadas foram extraídas do Relatório Final Rede Clínicas do Testemunho Sigmund Freud Associação Psicanalítica - Clínicas do Testemunho do Rio Grande do Sul, documento por nós consultado e utilizado como fonte de análise.

A equipe que começou a desenvolver o projeto junto ao primeiro edital (2013-2015) estava vinculada a Sigmund Freud Associação Psicanalítica. Porém, no segundo edital, a entidade que foi contemplada a firmar o convênio com a Comissão de Anistia foi o Instituto Appoa - Clínica, Intervenção e Pesquisa em Psicanálise, sede Porto Alegre. Essa modificação de instituição se deu por questões de cunho burocrático. Após a modificação institucional, a equipe do projeto seguiu e novos membros foram agregados ao grupo. 
A reparação dentro do Clínicas ocorre através de múltiplos dispositivos. Dentre os dispositivos adotados pelo projeto na sede de Porto Alegre estão os atendimentos individuais, os grupos de testemunhos, os grupos temáticos, as conversas públicas e as capacitações. Cabe ressaltar que tais dispositivos terão suas funções explicitadas quando abordamos a atuação do Clínicas. Conceitualmente entendemos que "todo dispositivo se define pelo que detém em novidade e criatividade, e que ao mesmo tempo marca a sua capacidade de se transformar, ou de desde logo se fender em proveito de um dispositivo futuro" (Deleuze citado em Boettcher, \& Pellanda, 2010, p. 98/99). Os dispositivos nos ajudam a pensar as sequelas e as reminiscências deixadas pela violência dos agentes estatais. Este processo objetiva viabilizar que o projeto realize atendimentos individuais e coletivos, nos quais a atenção se centrasse na escuta, em quem narra e no que é narrado, nas histórias que são enunciadas.

Os atendimentos individuais se constituem como espaços de psicoterapia. Esse espaço significa potências, pois é através da palavra, do ato de falar que tais possibilidades são construídas, por isso o terapeuta tem um papel fundamental que é o de escutar, de suportar aquilo que está sendo dito. Essa escuta contribui para que a pessoa recupere a sua dignidade que havia sido suspensa e possibilita que seja realizada a elaboração psíquica, conforme nos ensina Vital Brasil (2015).

Conforme a equipe clínica, a busca de atendimento individual foi motivada principalmente pelos seguintes fatores: o sofrimento direito ocasionado pelo silenciamento e não reconhecimento estatal; a ausência de espaços (sociais e familiares) destinados a receber e escutar as suas narrativas traumáticas sem as colocá-las em cheque; a manifestação de doenças psicossomáticas e repetições compulsórias até não passíveis de elaboração; experiências de (re)traumatizações propiciadas junto aos órgãos oficiais que buscavam aferir uma nova verdade sobre o ocorrido durante a ditadura civil-militar e ausência de acompanhamento para depor nesses espaços; a necessidade de reiniciar o acompanhamento terapêutico, tendo em vista a existência de um espaço especializado; procuraram devido aos eventos que abordavam a temática do cinquentenário do golpe civil-militar, fator que desencadeou (re)atualizações e despertou o devir de memória; consequência do trabalho reali- zado junto ao grupo de testemunho, muitos sentiram necessidade de aprofundar o seu processo de elaboração e alguns sentiram necessidade após seus parentes ingressarem no projeto e se permitiram a pensar sobre as vivências familiares, conforme consta no relatório da Sigmund Freud.

Outro dispositivo fundamental dentro do projeto são os grupos de testemunhos, esses se constituem como um espaço misto, essencialmente coletivo e público, mas que possibilita momentos de elaboração individual, para (re)significar suas vivências.

No projeto-piloto foram constituídos dois grupos de testemunhos, um com encontros na quarta-feira e o outro se reunia na quinta-feira. $\mathrm{O}$ grupo de quarta possuía encontros semanais, e durou de setembro de 2013 e até junho de 2015. Sua constituição era múltipla, ou seja, tinham filhos de afetados e uma pessoa que havia sido afetado diretamente. Teve, ao longo do transcurso, número variado de membros e, ao seu fim, havia oito integrantes. Uma integrante do grupo ficou enferma e, desde então, esteve ausente por um período. Essa situação alterou a dinâmica grupal, fazendo com que os testemunhos se focassem na memória, no "que foi silenciado pelos pais e também por reconhecerem lacunas importantes na história da família" (Sigmund Freud Associação Psicanalítica, 2015).

Já o grupo de quinta tinha periodicidade quinzenal. Sua constituição ocorreu em agosto de 2014 e durou até junho 2015 e, em seu encerramento, havia nove membros. Os compuseram afetados diretos, filhos e parentes de segunda geração. $\mathrm{E}$ as principais questões do grupo pontuavam a narrativa, a memória e como essas atuam como um gatilho de compartilhamento de histórias. Ainda das experiências dos grupos de testemunhos foi produzido um insumo, um livro intitulado "Os Arquivos da Vó Alda" composto de narrativas e memórias, o que demonstra um trabalho de composição, caracterizado pela aquisição de voz dos integrantes do projeto. Além do livro, através dos grupos foi gestada a criação do Coletivo de Filhos e Neto do Rio Grande do Sul, por Memória, Verdade e Justiça, criação formalizada através de uma Audiência Pública realizada no dia vinte quatro de abril de 2015, em Porto Alegre. Esse espaço foi marcado pelo compartilhamento de testemunhos, os quais foram previamente confeccionados dentro dos grupos, demonstrando um preparo e um cuidado antes que as vivências fossem coletivizadas, ou seja, devolvidas ao laço social. 
Durante a execução do projeto-piloto, foi detectada uma necessidade de interiorização do projeto, devido à dificuldade de acesso dos residentes no interior do Estado. Nesse sentido, ficou registrada a necessidade de criação de grupo de testemunhos e de realização de conversas públicas no interior, para, assim, levar a cabo a função de interiorizar o projeto. O rumar ao interior surgiu devido ao desconhecimento das histórias da repressão fora da capital e da dificuldade de permanente deslocamento à capital por aqueles que gostariam de ingressar no projeto, tais constam no relatório do projeto.

Já a proposta do grupo temático consiste em um espaço para trabalhar sobre questões específicas, a partir de um tema gerador, com o número máximo de dez sessões para abordá-las. Até o fim de 2016, não existia nenhum grupo temático na sede de Porto Alegre. Esse dispositivo surge apenas no segundo edital.

Outro dispositivo importante na articulação do projeto são as Conversas Públicas. Elas se constituem como um espaço de troca, compartilhamentos sobre o que ocorreu durante a ditadura civil-militar. Aspecto fundamental é que as conversas articulam a equipe do projeto, a sociedade civil, a comunidade acadêmica e todos os nichos sociais que possuem interesse em participar. As conversas públicas possuem metodologia diversa. Em algumas é utilizada uma fala central para conduzir o espaço, em outras, os gatilhos disparadores são manifestações artísticas, portanto, não há uma rigidez quanto à forma. Há por parte da equipe uma preocupação em descentralizar tais atividades, levando-as para o interior do Rio Grande do Sul. No primeiro edital apenas a cidade de Pelotas foi contemplada com a conversa, já no segundo edital, o dispositivo ocorreu em diversas cidades, tais como Rio Grande, São Leopoldo e Caxias do Sul, conforme consta no site institucional. A descentralização do projeto objetiva que as pessoas conheçam mais sobre o contexto repressivo que ocorreu no interior do estado e busca também ouvir histórias sobre as vivências frente ao terror estatal.

Por fim, temos as capacitações que possuem o objetivo de instrumentalizar a maneira de atuação das pessoas que lidam com sujeitos que foram e são vítimas da violência de Estado. Além disso, busca estimular o compartilhamento de experiência entre os elaboradores dos serviços públicos, com a intenção de traçar e elaborar estratégias de intervenção. As capacitações são fundamentais, já que demonstram para além dos afetados, direta ou indiretamente, que toda sociedade foi impactada pela violência estatal.

Ao investirmos esforços no projeto de reparação psíquica através de uma política estatal, investimos também na potência reparatória do testemunho reparação simbólica e psíquica, isso se justifica por não acreditarmos na possibilidade de conciliação com o passado, acharmos necessário revisitarmos um dos capítulos mais bárbaros da história dos brasileiros, como pontua Kolker (2015).

Cabem algumas observações metodológicas sobre o conceito de reparação psíquica: primeiramente, a reparação psíquica não busca a paz através do esquecimento do vivido, o que se busca é recompor individual e coletivamente o episódio traumático. A Clínica do testemunho é "uma clínica do laço social, ao criar condições de possibilidade para que se escutem e se criem novos testemunhos, conectando intergeracionalmente a atualidade do horror que ainda marca nosso tecido social" (Indursky, \& Piccinini, 2015, p. 9). Interessa-nos, possibilitar esses espaços públicos de fala e escuta, mantidos pelo Estado brasileiro, onde as narrativas testemunhais se tornam possíveis, são preparadas, sustentadas e escutadas, na perspectiva do cuidado e do acolhimento.

A reparação psíquica não é dirigida apenas aos sujeitos que foram afetados, se direciona também a sociedade civil como um todo, pois, ao repensar esse passado autoritário, possibilita (re)significar toda violência estatal, desde a ditatorial até a atual, que nos constitui enquanto sociedade. Para os que foram afetados diretamente, a reparação psíquica não significa curar as sequelas geradas pela violência estatal, significa criar possibilidades de reelaborar, de recompor sua vida. Podemos dizer que a reparação por via do testemunho possibilita recompor aspectos de sua identidade, e diz respeito as estratégias e as possibilidades de resistência. Elaborar a vivência traumática não significa apagá-la, e sim reforçar a coragem, a memória, a resistência, conforme Pereira (2015).

Além disso, a reparação psíquica instaura outra lógica na perspectiva reparatória, as demais medidas se configuram como procedimentos pontuais, burocráticos, nas quais há uma previsibilidade racional, pois há requisitos que necessitam ser preenchidos para que a pessoa receba a respectiva reparação. Esses processos não contemplam a subjetividade daqueles que foram afetados pela violência estatal. A reparação 
psíquica, através do Clínicas, instaura um espaço onde a fala, a escuta e a alteridade tornam-se centrais, cabendo as verdades subjetivas, as narrativas, as vivências, tudo que não pode ser quantificado, ou racionalizado. Pois, o testemunho é sempre um ato de cocriação, por assim ser, não é estanque, não nos diz uma verdade pontual, já que o testemunho é sempre fabricado "à medida que as condições sociais de recepção de seu relato são possibilitadas” (Indursky, \& Szuchman, 2014, p. 51). Aqui o paradigma não é a verdade absoluta, pontual, factual e científica, e sim uma verdade subjetiva e histórica na qual cada vivência seja importante para construirmos uma narrativa pública sobre passado autoritário, para, assim, recompormos o caleidoscópio da história.

Dentro da lógica da reparação psíquica e dos testemunhos, o aspecto do cuidado é fundamental, pois não queremos que ocorram reflexos danosos àqueles(as) que foram afetados pelo terrorismo de estado. Esse passado permeado por violência e injustiças foi brutalmente silenciado, conforme assenta Mate (2005). A violência estatal tocou a pele de muitos e impactou o laço social, mas a experiência da violência tem seu lado oculto, que só a testemunha pode narrar, só ela pode revelar. Por isso, a testemunha "tem uma perspectiva da verdade que só ela poderá dizer na forma de testemunho" (Ruiz, 2014, p. 59), já que ela teve a experiência do toque, e o testemunho significa o oposto dessa violência, aquilo que antes era silêncio, torna-se agora "linguagem compartilhada, vivida, sentida diferente, mas não ressentida" (Oliveira, 2012, p.245).

Através da escuta, do acolhimento, esse sujeito reescreve a sua história, nesse contexto sua narração não é (e nem será) questionada, pois, a temporalidade do trauma e do testemunho é outra, e não responde as verdades científicas cartesianas, não se inscrevem em uma linearidade temporal. Assim, como o tempo do trauma, o tempo do testemunho não é linear, a testemunha tem a autoridade de narrar a sua experiência. Os testemunhos possibilitam o deslocamento, uma experiência que era dimensionada como privada/individual, após a sua enunciação e recebimento, passa a figurar na ordem do coletivo, pois essa vivência partilhada trouxe elementos que compõe a memória social, algo que é importante para a coletividade. Além disso, ao partilhar com o laço social, torna-se público os efeitos da ação estatal, fora que o laço social é responsável por aquilo que o Estado cometeu consigo, pois promoveu tal violência e posteriormente, a silenciou. O testemunho situa-se entre "o dito e o não dito" (Conte, 2014, p. 87). Como já dito anteriormente, a escuta, é o elemento fundamental, ou seja, devolve a palavra e respeita o tempo e respeita aquilo que ainda não pode ser dito, revelado. Dessa forma, a abertura entre o vivenciado e o não dito, estabelece um elo simbólico que possibilita a elaboração psíquica.

Como nos afirma Martín-Baró (1997), o psicólogo não deve se omitir frente ao terrorismo do estado, e sim deve colocar seu saber em uma oposição crítica a esses fenômenos de autoritários. É isso que o Clínicas se propõe ao realizar uma clínica política que problematiza as arbitrariedades de ontem e as violências de hoje, a partir dos sujeitos que foram afetados e sem perder de vista o impacto que esses arbítrios causam no tecido social.

\section{Considerações finais}

Ao longo desse percurso evidenciamos o trabalho social que é necessário fazer para se narrar o trauma, este como experiência coletiva e não somente individual, algo que afeta o corpo social, desde a maneira de vivenciar até o ato de narrar. Assim firmamos um compromisso ético dentro desse escrito e atribuímos ao testemunho uma potência, pois os testemunhos atuam como relâmpagos, como feixes e realizam uma ruptura com o passado amortecido e marcado pelo silenciamento.

O Projeto Clínicas do Testemunho cria uma atmosfera de cuidado, pois propicia o acolhimento e a escuta, visando a não (re)traumatização. Para isso, tece um espaço social destinado a enunciação dos testemunhos, sendo essas construções narrativas que possibilitam múltiplas perspectivas sobre o passado autoritário, suas presentificações e as reminiscências. Os testemunhos possibilitam outras fontes e narrativas para comporem a nossa história, passando a contrapelo a história oficial, que se alicerça nos grandes feitos, nos grandes homens. Ao lançarmos luz ao Clínicas, mostramos que a nossa sociedade ainda não reconhece seu passado e não compreende que as relações estabelecidas na ditadura civil-militar dificultam a efetivação dos direitos humanos, dos limites institucionais e democráticos, e dificulta pensarmos os direitos transicionais - a memória, a verdade e justiça.

Conforme demonstrado ao longo do escrito, há prejuízo no afastamento temporal que ocorreu 
dos danos causados pela violência estatal e a implementação do projeto de reparação psíquica bancado pelo estado brasileiro. O principal prejuízo por nós verificado foi o silenciamento social que fez com essas vivências ficassem resguardadas no âmbito individual e quando socializadas eram postas em cheque. Esse lapso temporal em nenhum momento se constitui como um impeditivo para o trabalho de elaboração psíquica, pois o tempo do trauma, a sua atualização e elaboração, não responde a uma linearidade cronológica. A Clínica do Testemunho, por se constituir como uma clínica política, não focaliza na ideia de cura e se estrutura na potência do testemunho e no ato de transmitir, em devolver a experiência traumática (re)elaborada para a coletividade no intuito de compreender que a história individual constitui e se reflete no coletivo.

A experiência clínica vivenciada em Porto Alegre se constituiu frutífera, pois dela renderam insumos e uma meta de interiorização do projeto, buscando ampliar os núcleos e as possibilidades de recontar as histórias vivenciadas no interior do estado do Rio
Grande do Sul. Os dispositivos clínicos elencados pela sede de Porto Alegre demonstram as potencialidades do projeto, que atribui a centralidade aos sujeitos que foram afetados pela violência de estado, pois o protagonismo do Clínicas consiste na enunciação das vivências, tornando-as experiências. Enfim, o Projeto Clínicas busca interrogar nosso passado, objetivando que o tecido social o compreenda e (re)signifique, com a intenção de cessar os repliques. A atuação do Clínicas nos permite tensionar as instituições e suas atuações, para repensarmos os limites dessas. Os testemunhos como dispositivos de verdades, propiciam deslocamento dos sujeitos. Antes eram afetados e agora com a mudança discursiva tornam-se sujeitos históricos, pois, através da narração de suas experiências, esses auxiliam a construir uma narrativa pública sobre o passado e suas atualizações. As enunciações testemunhais são atos que gritam por verdade, memória, justiça social e justiça procedimental, para assim permitirmos a construção de uma memória histórica, permeada por múltiplas histórias, que focalizam nos direitos humanos e na alteridade.

\section{Referências}

Abrão, P. (2012). Fazer justiça no Brasil: a terceira fase da luta pela anistia. In Abrão, P., Genro, T. Os direitos da transição e a democracia no Brasil: estudos sobre justiça de transição e teoria da democracia (pp. 109-120). Belo Horizonte, MG: Fórum.

Altounian, J. (2012). Exumar um traço e fazer ouvir uma voz exige várias gerações. Revista Brasileira de Psicanálise, 46(3):106-120.

Baggio, R. C; Miranda, L. C. (2010). Poder judiciário e estado de exceção no Brasil: As marcas ideológicas de uma cultura jurídica autoritária. Revista do Instituto de Hermenêutica Jurídica, 8(8): 149-169.

Bauer, C, S. (2006) Avenida João Pessoa, 2050 - 3o. andar : terrorismo de Estado e ação de polícia política do Departamento de Ordem Política e Social do Rio Grande do Sul (1964-1982) (Dissertação de mestrado). Instituto de Filosofia e Ciências Humanas, Universidade Federal do Rio Grande do Sul, Porto Alegre, RS.

Benjamin, W. (2012). Experiência e pobreza. In W. Benjamin, Magia e técnica, arte e poética: ensaios sobre literatura e história da cultura (pp. 123-128, 8a ed., S. P. Rouanet, trad. 8 ed.). São Paulo, SP: Brasiliense.

Boettcher, D. M., \& Pellanda, N. M. C. (2010.) Vivências autopoiéticas. Santa Cruz do Sul, RS: Edunisc.

Brasil. (1995, 5 de dezembro). Lei No 9.140, de 4 de dezembro de 1995. Reconhece como mortas pessoas desaparecidas em razão de participação, ou acusação de participação, em atividades políticas, no período de 2 de setembro de 1961 a 15 de agosto de 1979, e dá outras providências. Diário Oficial da União.

Brasil. (2002, 14 de novembro). Lei No 10.559. de 13 de novembro de 2002. Regulamenta o art. 80 do Ato das Disposições Constitucionais Transitórias e dá outras providências. Diário Oficial da União.

Brasil. (2011a, 18 de novembro). Lei No 12.527, de 18 de novembro de 2011. Regula o acesso a informações previsto no inciso XXXIII do art. 5o, no inciso II do $\$ 30$ do art. 37 e no $\$ 20$ do art. 216 da Constituição Federal; altera a Lei no 8.112, de 11 de dezembro de 1990; revoga a Lei no 11.111, de 5 de maio de 2005, e dispositivos da Lei no 8.159, de 8 de janeiro de 1991; e dá outras providências. Diário Oficial da União.

Brasil. (2011b, 18 de novembro). Lei № 12.528, de 18 de novembro de 2011. Cria a Comissão Nacional da Verdade no âmbito da Casa Civil da Presidência da República. Diário Oficial da União. 
Carrillo, F. R. (2009). Memória histórica: o papel da cultura nas transições. Revista Anistia Política e Justiça de Transição, (2): 32-49.

Conte, B. S. (2014). Testemunho: reparação do trauma é possível? In Clínicas do testemunho: reparação psíquica e construção de memórias (pp. 83-92). Porto Alegre, RS: Criação Humana.

Cunha, P. R. (2010). Militares e anistia no Brasil: um dueto desarmônico. In E. Teles, \& V. P. Safatle, O que resta da ditadura: a exceção brasileira (pp. 15- 40). São Paulo, SP: Boitempo.

Ferenczi, S. (2011a). Dois tipos de neuroses de guerra (histeria). In S. Ferenczi, Obras completas (Vol. 2, pp. 293-311). São Paulo, SP: Martins Fontes.

Ferenczi, S. (2011b). Reflexões sobre o trauma. In S. Ferenczi, Obras completas (Vol. 4, pp. 125-136). São Paulo, SP: Martins Fontes.

Freud, S. (1997). Primeiras publicações psicanalíticas (1893-1899). S. Freud, Edição standard brasileira das obras psicológicas completas de Sigmund Freud (Vol. 3). Rio de Janeiro, RJ: Imago.

Freud S., \&, Breuer J. (1995). Estudos sobre a histeria (1893-1895). In S. Freud, Edição standard brasileira das obras psicológicas completas de Sigmund Freud (Vol. 2). Rio de Janeiro, RJ: Imago.

Gil, A. C. (1987). Métodos e técnicas de pesquisa social. São Paulo, SP: Atlas.

Indursky, A. C., \& Piccinini, C. A. (2015). O testemunho como ferramenta clínico-política. Mudanças-Psicologia da Saúde, 23(1), 1-9. https://doi.org/10.15603/2176-1019/mud.v23n1p1-9

Indursky, A. C., \& Szuchman, K. (2014) Grupos do testemunho: função e ética do processo testemunhal. In Clínicas do testemunho: reparação psíquica e construção de memórias (pp. 49-66). Porto Alegre, RS: Criação Humana.

Kehl, M. R. (2004). Três perguntas sobre o corpo torturado. In I. Keil, \& M. Tiburi (Org.), O corpo torturado (pp. 9-21). Porto Alegre, RS: Escritos.

Kehl, M. R. (2010). Tortura e sintoma social. In E. Teles, \& V. Safatle (Orgs.), O que resta da ditadura (pp. 123-132). São Paulo, SP: Boitempo.

Keil, I. (2004). Nas rodas do tempo. In I. Keil, \& M. Tiburi (Org.), O corpo torturado (pp. 41-61). Porto Alegre, RS: Escritos.

Kolker, T. (2015) Notas sobre o papel do testemunho e do dispositivo clínico-políticono processo de reparação dos afetados pela violência de Estado. In Brasil. Ministério da Justiça. Comissão de Anistia. Uma perspectiva clínico- política na reparação simbólica: Clínica do Testemunho do Rio de Janeiro (pp 57-74). Rio de Janeiro, RJ: Instituto Projeto Terapêuticos.

Koltai, C. (2016). Entre psicanálise e história: o testemunho. Psicologia USP, 27(1): 24-30. https://doi. org/10.1590/0103-6564D20150009

Levi, P. (1988). É isto um homem? (L. Del Re, trad). Rio de Janeiro, RJ: Rocco.

Lira, E., \&Weinstein, E. (1984). Psicoterapia y represión política. Buenos Aires: Siglo Veintiuno.

Losicer, E. (2015). Potência do testemunho: reflexões clínico-políticas. . In C. Cardoso, M. Felippe, \& V. Vital Brasil (Orgs.), Uma perspectiva clínico-política na reparação simbólica: Clínica do Testemunho do Rio de Janeiro (pp. 29-36). Brasília, DF: Ministério da Justiça.

Martin-Baró, I. (1997). O papel do psicólogo. Estudos de Psicologia (Natal), 2(1): 7-27. https://doi.org/10.1590/ S1413-294X1997000100002.

Mate, R. (2005). Memórias de Auschwitz, atualidade e política. São Leopoldo, RS: Nova Harmonia.

Mezzaroba, G. (2006) Um acerto de contas com o futuro: a anistia e suas consequências: um estudo do caso brasileiro. São Paulo, SP: Humanitas.

Ocariz, M. C., Rudge, A. M., Sciulli, M. C. G., Pereira, M. L. I. E., \& Navarro, N. C. (2014). O trauma, a palavra e a memória na Clínica do Testemunho Instituto Sedes Sapientiae. Percurso, 52. Recuperado de http://revistapercurso.uol.com.br/index.php?apg=artigo_view\&ida=1099\&ori=edicao\&id_edicao=52 
Oliveira, R. C. (2012). Do corpo colonizado à linguagem do "avesso" na América Latina: papéis dos testemunhos cartográficos para uma justiça de transição. Dissertação de mestrado, Pontifícia Universidade Católica, Porto Alegre, RS.

Padrós, E. (2005). Como el Uruguay no hay... terror de Estado e segurança nacional Uruguai (1968-1985 : do Pachecato à ditadura civil-militar. Tese de doutorado, Universidade Federal do Rio Grande do Sul, Porto Alegre, RS.

Pereira, A. W. (2010). Ditadura e repressão: o autoritarismo e o estado de direito no Brasil, no Chile e na Argentina. São Paulo, SP: Paz e Terra.

Pereira, M. L. I. E. M. (2015) Possibilidades de narrar a experiência traumática: testemunhando a transmissão. In M. C. Ocariz (Org.), Violência de Estado na ditadura civil-militar brasileira (1964-1985): efeitos psíquicos e testemunhos clínicos (pp. 175-186). São Paulo, SP: Escuta.

Perrone, C., \& Moraes, E. G. (2014). Do trauma ao testemunho: um caminho possível de subjetivação. In Clínicas do testemunho: reparação psíquica e construção de memórias (pp. 31-46). Porto Alegre, RS: Criação Humana.

Rodrigues, N. C., \& Véras Neto, F. Q. (2016). Os ecos do passado e os testemunhos das mulheres que militaram frente à ditadura militar brasileira: exemplos de luta, resistencia e de afirmação dos direitos das mulheres. In R. M. C. Machado, \& A. M. Castro (Orgs.). Direitos das mulheres no Brasil: experiências de norte a sul (pp. 135-154). Manaus, AM: UEA Edições.

Ruiz, C. M. M. B. (2014) Estatuto epistêmico do Testemunho das vítimas: o desaparecido, paradigma do testemunho indizível. Revista Anistia Política e Justiça de Transição, 9, 50-72.

Sigmund Freud Associação Psicanalítica. (2015). Relatório final Rede Clínicas do Testemunho. Recuperado de http://www.justica.gov.br/central-de-conteudo/anistia/anexos/relatorio-final-sigmund-freud-associacao-psicanalitica.pdf

Trachtenberg, A. R. (2013). Transgeracionalidade de escravo a herdeiro: um destino entre gerações. Porto Alegre, RS: Sulina.

Vannuchi, M. B. C. C. (2014). Afinal, o que faz um psicanalista na Clínica do Testemunho? Percurso, 52. Recuperado de http://revistapercurso.uol.com.br/index.php?apg=artigo_view\&ida=1096\&ori=autor\&letra=V

Vianna, H. B. (1994) Não conte a ninguém: História das sociedades psicanalíticas do Rio de Janeiro. Rio de Janeiro, RJ: Imago.

Viñar, M. (1993). Fracturas de Memória: crónicas para una memoria por venir. Montevideo: Trilce.

Vital Brasil, V. (2015). Testemunho da Verdade e efeitos de reparação psíquica. In C. Cardoso, M. Felippe, \& V. Vital Brasil (Orgs.), Uma perspectiva clínico-política na reparação simbólica: Clínica do Testemunho do Rio de Janeiro (pp. 37-56). Brasília, DF: Ministério da Justiça.

\section{Natália Centeno Rodrigues}

Mestre em Direito e Justiça Social pela Universidade Federal do Rio Grande - FURG, Rio Grande - RS. Brasil. Bacharel em História e Direito pela FURG. Professora tutora do curso de história modalidade EaD da FURG/UAB. Pesquisadora do Grupo Transdisciplinar de Pesquisa Jurídica para a Sustentabilidade (CNPQ/FURG). Coordenadora da linha de pesquisa Justiça de Transição no Brasil e os processos latino-americanos no pós-ditatoriais. Advogada voluntária junto ao Defensa (projeto de extensão) da Universidade Federal de Pelotas - UFPel.

E-mail: naticenteno@gmail.com

\section{Francisco Quintanilha Véras Neto}

Doutor emDireito pela Universidade Federal do Paraná-UFPR, Curitiba-PR. Brasil. Mestre emDireito pela Universidade Federal de Santa Catarina - UFSC, Florianópolis - SC. Brasil. Professor associado IV da Universidade Federal do Rio Grande - FURG, Rio Grande - RS. Brasil. Professor vinculado ao Programa de Pós-graduação em Direito da FURG. Professor coordenador do Grupo Transdisciplinar de Pesquisa Jurídica para a Sustentabilidade (CNPQ/FURG).

E-mail: quintaveras@gmail.com 


\section{Rodrigo Fernandes Teixeira}

Acadêmico do curso de Psicologia da Universidade Federal do Rio Grande - FURG, Rio Grande - RS. Brasil. Bolsista do Centro Regional de Estudos, Prevenção e Tratamento de Dependentes Químicos da FURG. Integrante do Grupo Transdisciplinar de Pesquisa Jurídica para a Sustentabilidade (CNPQ/FURG) vinculado à linha de pesquisa Justiça de Transição no Brasil e os processos latino-americanos no pós-ditatoriais.

E-mail: rodrigo.fds.t@gmail.com

Endereço para envio de correspondência:

Rio Solimões, 44, Parque Marinha

Rio Grande, RS.

CEP: 96215610.

Recebido 30/06/2017

Reformulação 17/09/2017

Aprovado 20/09/2017

Received 06/30/2017

Reformulated $09 / 17 / 2017$

Approved 09/20/2017

Recebido 30/06/2017

Reformulado 17/09/2017

Aceptado 20/09/2017

Como citar: Rodrigues, N. C., Véras Neto, F. Q., \& Teixeira, R. F. (2017). Reminiscências da violência estatal: a reparação psíquica através de uma clínica política. Psicologia: Ciência e Profissão, 37(n. spe), 133-148. https://doi.org/10.1590/1982-3703100002017

How to cite: Rodrigues, N. C., Véras Neto, F. Q., \& Teixeira, R. F. (2017). Reminiscences of state violence: the psychological repair through a political clinic. Psicologia: Ciência e Profissão, 37(n. spe), 133-148. https://doi.org/10.1590/1982-3703100002017

Cómo citar: Rodrigues, N. C., Véras Neto, F. Q., \& Teixeira, R. F. (2017). Reminiscencias de la violencia estatal: la reparación psíquica a través de una clínica política. Psicologia: Ciência e Profissão, 37(n. spe), 133-148. https://doi.org/10.1590/1982-3703100002017 